University of Nebraska - Lincoln

DigitalCommons@University of Nebraska - Lincoln

1983

\title{
The Transmission of Learned Behavior: An Observational Study of Father-Child Interactions During Fishing
}

Judy Diamond

University of Nebraska - Lincoln, jdiamond1@unl.edu

Alan B. Bond

University of Nebraska - Lincoln, abond1@unl.edu

Follow this and additional works at: https://digitalcommons.unl.edu/bioscibehavior

Part of the Behavior and Ethology Commons

Diamond, Judy and Bond, Alan B., "The Transmission of Learned Behavior: An Observational Study of Father-Child Interactions During Fishing" (1983). Papers in Behavior and Biological Sciences. 63.

https://digitalcommons.unl.edu/bioscibehavior/63

This Article is brought to you for free and open access by the Papers in the Biological Sciences at DigitalCommons@University of Nebraska - Lincoln. It has been accepted for inclusion in Papers in Behavior and Biological Sciences by an authorized administrator of DigitalCommons@University of Nebraska - Lincoln. 


\title{
The Transmission of Learned Behavior: An Observational Study of Father-Child Interactions During Fishing
}

\author{
Judy Diamond and Alan B. Bond \\ Chesapeake Bay Center for Environmental Studies, Smithsonian Institution \\ Corresponding author - Judy Diamond
}

\begin{abstract}
Mechanisms of transmission of learned behavior were described in terms of the behavioral interactions between fathers and their children as they fished from a pier on Maryland's Eastern Shore. Verbal and nonverbal behaviors were analyzed using hierarchical cluster analysis and the patterns of association in the behavioral repertoire were described in detail. Groupings of associated behaviors ranged from clusters suggestive of modeling or simple showing to complex combinations of behaviors involved in teaching. There were indications that the transmission behaviors varied with the content of the transmitted information and the role of the performer. Role differentiation in the transmission behaviors suggested the occurrence of two distinct patterns in the ontogeny of complex behaviors.
\end{abstract}

Keywords: teaching-modeling, cultural transmission, human ethology, fishing

\section{Introduction}

The pioneering investigations of Itani (1958), Kawai (1965), and Norton Griffiths (1969), involving the transmission of learned behavior in nonhuman animals, have generated great interest in the evolution of culture. This interest has focused on questions of phylogeny (Bonner, 1980; Mundinger, 1980) and survival value (Barkow, 1980), but there has been relatively little ethological work on the mechanisms of transmission. While there have been numerous efforts to de- scribe the content of cultural information ("meme" in Dawkins, 1976a; "culturgen" in Lumsden and Wilson, 1981), there has been no comparable attempt to describe the process of its transfer between generations.

Mundinger (1980) and Bonner (1980) have emphasized that cultural transmission is necessarily a behavioral process, involving social behaviors that enhance or direct the acquisition of adaptive skills. Bekoff (1977) includes such behaviors under three general groupings: observational learning or imitation, social play, and teaching. However, each of these categories has been plagued with difficulties of definition and interpretation (Barnett, 1968; Ewer, 1969; Davis, 1973; Bekoff, 1976). In the case of teaching, in particular, there has been little success in delineating it from other forms of social learning, parental care or, for that matter, social communication (Humphrey, 1973). These difficulties could be resolved, in part, by acknowledging these categories as descriptive groupings and inferring common functions from the patterns of associations between behaviors, rather than from the measurement of their effects. An ethological methodology, studying the patterns of association between discrete, observable behaviors that occur during the natural transmission and acquisition of a skill, can provide a baseline description of transmission behaviors.

This study uses ethological methods to describe the repertoire and organization of behaviors involved in the transfer of information between fathers and their 
children while they fish. Fishing is one of a number of skills in which parental teaching likely plays a major role in the acquisition of the task by children. The complex structure of fishing activities and the richness of the surrounding environment should elicit a great diversity of teaching patterns, offering a reasonable assurance that the behavioral repertoire observed even over short periods of time is broadly representative. The behaviors used to teach children to fish should appear as coherent and identifiable groupings, thereby serving as a basis for an initial description of the transmission process. Eventually, comparisons across different tasks and cultural groups will be necessary to clarify the role of teaching in cultural transmission and to investigate the evolution of teaching behavior.

\section{Methods}

\section{Setting}

The study was conducted at a public fishing pier in Matapeake State Park on Maryland's Eastern Shore. The pier is roughly two meters across and extends out almost 300 meters into Chesapeake Bay. Use of the facility is unrestricted: no admission fee is charged and the pier remains open 24 hours a day. Throughout the daylight hours on summer weekends, the pier is crowded with from 25 to 100 people fishing and crabbing at any one time.

According to the Maryland State Park Service, bluefish (Pomatomus saltatrix) and spot (Leiostomus xanthurus) are the most common fish species caught from the pier. Bluefish schools approach the pier sporadically during the spring and fall. The pier has consequently gained a local reputation as one of the better shore areas on the Bay for catching "blues." Spot are found off the pier throughout the summer in dense schools of young individuals. Less common fish species caught off the pier include striped bass (Morone saxatilis), winter flounder (Pseudopleuronectes americanus), white perch (Morone americana), American eel (Anguilla rostrata), and common skate (Raja diaphanes).

Fish are typically caught using nylon line and one to three hooks on standard wood or fiberglass rods with reels. Adults commonly use weights on their lines, while young children use weights and/or bobbers. Bait generally consists of earthworms, grass shrimp, clams, silversides, small perch, or else spot caught off the pier. Lures are used only infrequently, and then usually by children.

During the summer months, the blue crab (Callinectes sapidus) occurs abundantly and predictably along the pilings of the pier and in the surrounding water. Maryland park rangers visit the pier several times a day to enforce state regulations concerning the size and number of crabs that may be caught. Crabs are typically captured using handlines and nets or lured into crab traps or pots. Bait usually consists of raw chicken parts, although occasionally eel, spot, or other fish may be used.

\section{Subjects and Procedure}

A total of 40 father-child dyads, including 30 male children and 10 female children, were observed and briefly interviewed as they fished and crabbed on Matapeake Pier. The children were between the ages of 5 and 10, with equal numbers of younger (5-7 year olds) and older subjects (8-10 year olds). The dyads were generally accompanied by friends and other family members, for a mean of $4.0 \pm 0.3$ individuals per group. Three-quarters of the subjects were Caucasian; the remainder were Black. Both fishing and crabbing were performed in one-third of the dyads, while the rest of the subjects engaged only in fishing activities.

Subjects were observed during daylight hours on Fridays, Saturdays, Sundays, and holidays between May 30 and October 1 of 1981. Adult-child groups were initially screened by the observer as they walked out on the pier for the first time that day. All groups were approached that contained at least one adult male and one child and who were carrying at least one fishing pole or rod. The adult male was asked his relationship to the child and the child's age. If the child was within the suitable age range, permission to observe them was requested. No groups refused permission to conduct the observations, although fathers who subsequently did not converse with their children in English were excluded from the study.

The observer sat on the pier within 2-3 meters from the subjects. Only a single observer was used in this study, in part to minimize subject reactivity, but also because a single, well-trained observer can often achieve higher reliabilities with large numbers of categories (Smith and Connolly, 1972). Data were re- 
corded by hand on 96-column IBM data sheets as a running sequence of two-digit numbers, each corresponding to one of 88 different behavioral categories (see Appendix A for category definitions). During each successive 3-minute interval, father and child behaviors were recorded on adjacent rows, such that the position of any given behavioral code corresponded to that of the simultaneously occurring behavior of the dyad partner. Interactions of the father or child with members of the group or with other people on the pier were recorded as ATTEND TO OTHER or VERBAL TO OTHER, while interactions with the observer were recorded as LOOK AT OBSERVER or VERBAL TO OBSERVER.

Subjects were observed continuously for up to two hours (= 40 sampling intervals), or for whatever period over 30 minutes that they remained on the pier. The mean observation time over all subjects was 96.2 \pm 8.7 minutes, while $48 \%$ of the subjects remained on the pier for the entire 2 hours. When subjects walked off the pier with the specified intention to return, forays that usually involved visits to the car or restrooms, they were noted as being OFF OF PIER, and the observer remained with the other group members or equipment until they returned. When the subjects began to pack their gear to leave for the day, or at the termination of a two-hour session, the observer approached them and requested permission to conduct a brief interview. The interview obtained information on the age and sex of the child, the subjects' residence and prior fishing experience, and the perceived role of parental teaching and family tradition in shaping their knowledge of fishing practices.

\section{Observation Code}

The 88 behavior categories used in this study (listed and defined in Appendix A) were formulated during pilot observations conducted over eight weekends in April and May 1981. The formulation involved a three-step process of generation, refinement, and verification.

Categories were generated primarily through observations of the ongoing behaviors, although several categories were initially derived from existing repertoire listings (Diamond, 1981; Blurton Jones, 1972; McGrew, 1972). A running list of behaviors was produced during the pilot observations, which served as the basis for most of the final categories used in the study. The process by which continuous perceptual input is initially translated into discrete categories has been discussed in detail elsewhere (e.g., Lorenz, 1960; Blurton Jones, 1972).

Category refinement consisted of lumping or splitting categories to produce functionally unified groups of behaviors. Decisions to alter the category scheme were based on several lines of evidence. First, behaviors were included in a single category if they showed similar structures (i.e., similar body movements or grammatical structure) or consistent temporal affinity, or if they were responded to by social partners in a similar manner or as a single unit. The category, CAST, for example, includes the separate actions of lift rod, hold rod back, arch back, look back, snap rod forward, and release reel. These actions were included in a single category because they were associated with one another temporally and were treated as a unified set by family members: when someone was told to "cast" or expressed their intention to "cast," it was always understood that they would engage in the entire act sequence. Motor action patterns were coded as whole-body or part-body actions (Marler and Hamilton, 1966) while verbal behaviors were coded as structurally and functionally related sentences (Weigel and Johnson, 1981).

The final procedure involved in category formulation consisted of verifying the category listing, which entailed a continuous series of test observations, in which omissions and ambiguities in the category listing were sought after and corrected. When subsequent observations entailed no additional category modifications, the list was considered suitable for use in the observational study.

\section{Results}

\section{Analytical Procedure}

For each of the 88 behavioral categories, a $t$ test of the significance of the difference in frequency between fathers and children, the two "actors" in the dyad, was performed. Given the large sample size involved $(1,282$ intervals), it was felt that were was a high likelihood of accepting differences as significant that actually accounted for only a trivial proportion of the variance. Acceptance of an actor difference was therefore based on whether the strength of the association exceeded $1 \%$ of the variance in the given behavior $\left(\omega^{2} \geq 0.01\right.$; Hays, 
1963). Means and standard deviations of the frequency of each behavior category for each actor are listed in Table 1. Behaviors that were judged significantly different in frequency between actors are indicated with asterisks.

The diversity of the behaviors recorded and the probability that they would be associated on multiple levels suggested that temporal associations among behaviors could best be displayed with hierarchical cluster analysis (Dawkins, 1976b; DeGhett, 1978). The BMDP clustering routine P1M was used, specifying the Pearson product-moment correlation as the measure of similarity and the average correlation as the criterion for combining clusters (Dixon and Brown, 1979).

Table 1. Mean Frequency per Interval (Standard Deviation)

\begin{tabular}{lll}
\hline & Father & Child \\
\hline & \multicolumn{2}{c}{ Nonverbal Categories } \\
\cline { 2 - 3 } PREPARE LINE & $0.12(0.36)$ & $0.05(0.23)^{a}$ \\
PREPARE BAIT & $0.14(0.38)$ & $0.11(0.34)$ \\
BAIT HOOK & $0.15(0.39)$ & $0.07(0.29)^{a}$ \\
CAST & $0.20(0.46)$ & $0.32(0.72)$ \\
HOLD ROD & $0.29(0.53)$ & $0.63(0.76)^{a}$ \\
REEL IN & $0.37(0.70)$ & $0.80(1.12)^{a}$ \\
REEL IN PARTIAL & $0.10(0.38)$ & $0.15(0.43)$ \\
TOUCH LINE & $0.03(0.19)$ & $0.12(0.36)^{a}$ \\
LET OUT LINE & $0.29(0.73)$ & $0.38(0.88)$ \\
UNSNAG & $0.05(0.22)$ & $0.10(0.33)$ \\
UNHOOK FISH & $0.11(0.32)$ & $0.02(0.16)^{a}$ \\
OR PREPARE LINE & $0.07(0.28)$ & $0.00(0.00)^{a}$ \\
OR PREPARE BAIT & $0.06(0.25)$ & $0.00(0.08)^{a}$ \\
OR BAIT HOOK & $0.12(0.34)$ & $0.01(0.09)^{a}$ \\
OR CAST & $0.18(0.45)$ & $0.02(0.14)^{a}$ \\
OR HOLD ROD & $0.09(0.33)$ & $0.05(0.24)$ \\
OR REEL IN & $0.10(0.35)$ & $0.13(0.56)$ \\
OR REEL IN PARTIAL & $0.02(0.17)$ & $0.02(0.19)$ \\
OR TOUCH LINE & $0.04(0.23)$ & $0.01(0.11)$ \\
OR LET OUT LINE & $0.03(0.20)$ & $0.09(0.48)$ \\
OR UNSNAG & $0.13(0.38)$ & $0.01(0.08)^{a}$ \\
MANIP FISH OTHER & $0.13(0.37)$ & $0.15(0.42)$ \\
MANIP TOGETHER & $0.13(0.41)$ & $0.13(0.40)$ \\
MANIP UNINTEND & $0.00(0.00)$ & $0.01(0.16)$ \\
MANIP FOOD CLOTHES & $0.05(0.23)$ & $0.08(0.30)$ \\
MANIP NONFISH OTHER & $0.01(0.10)$ & $0.02(0.14)$ \\
LOOK AT PREPARE LINE & $0.01(0.14)$ & $0.07(0.28)^{a}$ \\
LOOK AT PREPARE BAIT & $0.02(0.15)$ & $0.08(0.28)^{a}$ \\
LOOK AT BAIT HOOK & $0.02(0.15)$ & $0.09(0.30)^{a}$ \\
LOOK AT CAST & $0.07(0.30)$ & $0.17(0.43)^{a}$ \\
LOOK AT REEL IN & $0.34(0.63)$ & $0.51(0.73)^{a}$ \\
LOOK AT UNSNAG & $0.02(0.14)$ & $0.10(0.32)^{a}$ \\
LOOK AT UNHOOK FISH & $0.06(0.26)$ & $0.15(0.40)^{a}$ \\
LOOK AT OBJECT & $0.32(0.55)$ & $0.46(0.68)^{a}$ \\
LOOK AT LINE & $0.26(0.65)$ & $0.48(1.01)^{a}$ \\
LOOK AT BAIT & $0.13(0.39)$ & $0.27(0.56)^{a}$ \\
& &
\end{tabular}

Table 1. (Continued)

\begin{tabular}{|c|c|c|}
\hline & Father & Child \\
\hline & \multicolumn{2}{|c|}{ Nonverbal Categories } \\
\hline LOOK AT ANIMAL & $0.20(0.49)$ & $0.35(0.67)^{a}$ \\
\hline LOOK AT OBSERVER & $0.04(0.19)$ & $0.15(0.38)^{a}$ \\
\hline LOOK AWAY & $0.04(0.20)$ & $0.16(0.39)^{a}$ \\
\hline SMILE & $0.02(0.15)$ & $0.07(0.27)$ \\
\hline DISTRESS & $0.00(0.00)$ & $0.03(0.18)^{a}$ \\
\hline AGGRESS & $0.00(0.05)$ & $0.00(0.05)$ \\
\hline COMFORT TOUCH & $0.02(0.14)$ & $0.01(0.08)$ \\
\hline GIVE & $0.15(0.39)$ & $0.04(0.22)^{a}$ \\
\hline TAKE & $0.06(0.25)$ & $0.01(0.09)^{a}$ \\
\hline SHOW & $0.06(0.24)$ & $0.14(0.38)^{a}$ \\
\hline GO NEXT TO & $0.07(0.26)$ & $0.07(0.28)$ \\
\hline GO AWAY FROM & $0.03(0.17)$ & $0.06(0.26)$ \\
\hline FISH NEXT TO & $0.00(0.06)$ & $0.00(0.06)$ \\
\hline FISH AWAY FROM & $0.02(0.14)$ & $0.03(0.19)$ \\
\hline HELP FOOD CLOTHES & $0.01(0.12)$ & $0.00(0.04)$ \\
\hline ATTEND TO OTHER & $0.70(0.75)$ & $0.71(0.85)$ \\
\hline \multirow[t]{2}{*}{ OFF OF PIER } & $0.06(0.24)$ & $0.10(0.29)$ \\
\hline & \multicolumn{2}{|c|}{ Verbal Categories } \\
\hline CALL & $0.05(0.22)$ & $0.10(0.36)$ \\
\hline SHOW VERBAL & $0.09(0.35)$ & $0.23(0.52)^{a}$ \\
\hline TELL & $0.54(0.92)$ & $0.20(0.51)^{a}$ \\
\hline TELL NOT & $0.22(0.54)$ & $0.04(0.21)^{a}$ \\
\hline NAME & $0.36(0.71)$ & $0.64(0.95)^{a}$ \\
\hline DESCRIBE WHAT & $0.17(0.45)$ & $0.18(0.46)$ \\
\hline DESCRIBE HOW & $0.09(0.33)$ & $0.01(0.12)^{a}$ \\
\hline DESCRIBE WHY & $0.03(0.18)$ & $0.01(0.08)$ \\
\hline DESCRIBE BY ANALOGY & $0.01(0.07)$ & $0.01(0.13)$ \\
\hline DESCRIBE BY EXAMPLE & $0.00(0.08)$ & $0.00(0.05)$ \\
\hline RELATE TO PAST & $0.01(0.09)$ & $0.02(0.14)$ \\
\hline RELATE TO FUTURE & $0.01(0.10)$ & $0.01(0.12)$ \\
\hline QUES WHAT & $0.08(0.30)$ & $0.29(0.57)^{a}$ \\
\hline QUES HOW & $0.01(0.13)$ & $0.04(0.22)$ \\
\hline QUES WHY & $0.01(0.09)$ & $0.04(0.25)$ \\
\hline QUES WHAT WANT & $0.06(0.24)$ & $0.02(0.13)$ \\
\hline QUES TO CONFIRM & $0.18(0.49)$ & $0.16(0.44)$ \\
\hline AGREE & $0.04(0.19)$ & $0.03(0.18)$ \\
\hline DISAGREE & $0.03(0.19)$ & $0.03(0.17)$ \\
\hline GIVE POS VALUE & $0.01(0.10)$ & $0.07(0.28)^{a}$ \\
\hline GIVE NEG VALUE & $0.00(0.06)$ & $0.08(0.31)^{a}$ \\
\hline PRAISE & $0.04(0.24)$ & $0.01(0.10)$ \\
\hline REPRIMAND & $0.02(0.15)$ & $0.00(0.03)$ \\
\hline COMPLAIN & $0.00(0.04)$ & $0.03(0.19)^{a}$ \\
\hline SAY DISLIKE & $0.00(0.00)$ & $0.00(0.04)$ \\
\hline EXPRESS ABILITY & $0.09(0.33)$ & $0.37(0.66)^{a}$ \\
\hline OFFER HELP & $0.01(0.10)$ & $0.00(0.04)$ \\
\hline ASK FOR HELP & $0.01(0.11)$ & $0.13(0.38)^{a}$ \\
\hline ASK PERMISSION & $0.00(0.04)$ & $0.09(0.31)^{a}$ \\
\hline JOKE & $0.02(0.15)$ & $0.02(0.14)$ \\
\hline REPEAT OWN VERBAL & $0.06(0.27)$ & $0.15(0.49)^{a}$ \\
\hline REPEAT OTHER VERBAL & $0.03(0.16)$ & $0.03(0.19)$ \\
\hline VERBAL TO OTHER & $0.65(0.75)$ & $0.56(0.77)$ \\
\hline VERBAL TO OBSERVER & $0.05(0.24)$ & $0.06(0.27)$ \\
\hline VERBAL TO ANIMAL & $0.00(0.04)$ & $0.03(0.18)^{a}$ \\
\hline
\end{tabular}

${ }^{a}$ Significant differences between father and child $\left(\omega^{2} \geq .01\right)$. 
Because of the sensitivity of the correlation coefficient to low-frequency events, behaviors in either actor category with five or fewer occurrences in the data set were excluded from the correlation analysis. Behaviors excluded from both actor groupings included AGGRESS, FISH NEXT TO, DISLIKE, and DESCRIBE BY EXAMPLE. Behaviors excluded from fathers only were DISTRESS, MANIP UNINTENDED, COMPLAIN, VERBAL TO ANIMAL, GIVE NEG VALUE, and ASK PERMISSION. Behaviors excluded from children only were OR PREPARE LINE, OR PREPARE BAIT, HELP FOOD CLOTHES, REPRIMAND, and OFFER HELP. In addition, OFF OF PIER was excluded from both actors on the grounds of its irrelevance to the rest of the analysis.

Three primary levels of association were extracted from the analysis and used in the display of the cluster analysis in Table 2. The minimum degree of association considered meaningful was a mean correlation of 0.06. For the given sample size, this correlation was significant at $p=0.01$. Because a variable can occupy only one position in a clustering pattern, hierarchical cluster analysis will display only the strongest multivariate associations and will necessarily overlook some significant variable relationships. To counteract this deficiency to some degree, additional associations involving mean correlations of 0.1 or better are described in the text when they appear relevant to a full understanding of the data structure.
Observer reliability was assessed for each variable across all dyads using the split-half technique in the SPSS RELIABILITY subroutine (Hull \& Nie, 1979). The mean Guttman split-half coefficient, taken across all variables used in both actors in the correlation analysis, was 0.75 . Only five categories exhibited reliabilities of less than 0.4: LOOK AT BAIT HOOK, MANIP NONFISH OTHER, DISAGREE, DESCRIBE BY ANALOGY, and RELATE TO PAST. Similarly high intraobserver reliabilities have been observed in other ethological studies of human behavior (Smith \& Connolly, 1972).

\section{Frequency Differences}

Behaviors occurring significantly more frequently in fathers. Fathers were observed to engage in PREPARE LINE, BAIT HOOK, and UNHOOK FISH significantly more often than children. In general, fishing on the dyad partner's rod ("OR fishing") displayed strong contrasts across actor. With the exceptions of OR REEL IN and OR LET OUT LINE, which were primarily related to crabbing, fathers performed OR fishing actions more frequently than children. This included particularly OR BAIT HOOK, OR CAST, and OR UNSNAG. Children effectively did not perform OR PREP LINE or OR PREP BAIT. Descriptions, particularly DESCRIBE WHAT and DESCRIBE HOW, were among the most frequent verbal behaviors observed in fathers, occurring significantly more

Table 2. Cluster Analysis ${ }^{a}$

\begin{tabular}{|c|c|c|}
\hline & Father & Child \\
\hline 1 & $\begin{array}{l}\text { PREPARE LINE } \\
\text { LOOK AT PREPARE LINE } \\
\text { OR PREPARE LINE }\end{array}$ & $\begin{array}{l}------ \\
\text { PREPARE LINE } \\
\text { LOOK AT PREPARE LINE }\end{array}$ \\
\hline 2 & $\begin{array}{l}\text { PREPARE BAIT, BAIT HOOK } \\
\text { CAST, HOLD ROD, REEL IN PARTIAL }\end{array}$ & $\begin{array}{l}----- \\
-----\end{array}$ \\
\hline 3 & ----- & OR CAST, OR HOLD ROD, OR REEL IN PARTIAL \\
\hline 4 & $\begin{array}{l}\text { LOOK AT PREPARE BAIT } \\
\text { LOOK AT BAIT HOOK, PRAISE }\end{array}$ & $\begin{array}{l}\text { PREPARE BAIT, BAIT HOOK } \\
------\end{array}$ \\
\hline 5 & ----- & QUES HOW, ASK FOR HELP \\
\hline 6 & $\begin{array}{l}\text { LOOK AT CAST } \\
------ \\
\text { LOOK AT BAIT }\end{array}$ & $\begin{array}{l}\text { CAST } \\
\text { HOLD ROD, REEL IN PARTIAL } \\
\text { LOOK AT BAIT }\end{array}$ \\
\hline
\end{tabular}




\begin{tabular}{|c|c|c|}
\hline & Father & Child \\
\hline 8 & $\begin{array}{l}\text { TOUCH LINE } \\
\text { OR TOUCH LINE }\end{array}$ & $\begin{array}{l}------ \\
\text { TOUCH LINE }\end{array}$ \\
\hline 9 & $\begin{array}{l}\text { REEL IN, LET OUT LINE, LOOK AT LINE } \\
\text { LOOK AT REEL IN }\end{array}$ & $\begin{array}{l}------ \\
\text { REEL IN, LET OUT LINE, LOOK AT LINE }\end{array}$ \\
\hline 10 & $\begin{array}{l}------ \\
\text { GO NEXT TO } \\
\text { ATTEND TO OTHER, VERBAL TO OTHER } \\
\text { GO AWAY FROM }\end{array}$ & $\begin{array}{l}\text { CALL } \\
------ \\
------ \\
------\end{array}$ \\
\hline 12 & $\begin{array}{l}\text { UNHOOK FISH } \\
\text { LOOK AT UNHOOK FISH } \\
\text { LOOK AT ANIMAL } \\
------\end{array}$ & $\begin{array}{l}\text { LOOK AT UNHOOK FISH } \\
\text { UNHOOK FISH } \\
\text { LOOK AT ANIMAL } \\
\text { GIVE POS VALUE }\end{array}$ \\
\hline $\begin{array}{l}14 \\
15\end{array}$ & $\begin{array}{l}\text { UNSNAG } \\
\text { LOOK AT UNSNAG } \\
\text { OR UNSNAG }\end{array}$ & $\begin{array}{l}----- \\
\text { UNSNAG } \\
\text { LOOK AT UNSNAG }\end{array}$ \\
\hline $\begin{array}{l}16 \\
17\end{array}$ & $\begin{array}{l}\text { OR PREPARE BAIT, OR BAIT HOOK } \\
\text { OR CAST, OR HOLD ROD, OR REEL IN, }\end{array}$ & $\begin{array}{l}\text { LOOK AT PREPARE BAIT, LOOK AT BAIT HOOK } \\
\text { LOOK AT CAST }\end{array}$ \\
\hline & $\begin{array}{l}\text { GIVE, TAKE } \\
\text { OR REEL IN PARTIAL }\end{array}$ & $\begin{array}{l}------ \\
\text { MANIP TOGETHER }\end{array}$ \\
\hline 18 & $\begin{array}{l}\text { MANIP TOGETHER } \\
\text { OR LET OUT LINE }\end{array}$ & ------ \\
\hline $\begin{array}{l}19 \\
20\end{array}$ & $\begin{array}{l}------ \\
------ \\
------\end{array}$ & $\begin{array}{l}\text { QUES WHAT WANT } \\
\text { OR BAIT HOOK } \\
\text { OR UNSNAG }\end{array}$ \\
\hline 21 & $\begin{array}{l}----- \\
-----\end{array}$ & $\begin{array}{l}\text { OR REEL IN, OR LET OUT LINE } \\
\text { ATTEND TO OTHER, VERBAL TO OTHER }\end{array}$ \\
\hline 22 & ----- & OR TOUCH LINE \\
\hline 23 & $\begin{array}{l}\text { FISH AWAY FROM } \\
------\end{array}$ & $\begin{array}{l}----- \\
\text { MANIP FISH OTHER }\end{array}$ \\
\hline 24 & MANIP FISH OTHER & $\overline{\text { VERBAI TOOBSERVER }}$ \\
\hline 26 & $\begin{array}{l}------ \\
\text { CALL }\end{array}$ & $\begin{array}{l}\text { FISH AWAY FROM } \\
------\end{array}$ \\
\hline $\begin{array}{l}27 \\
28\end{array}$ & $\begin{array}{l}------ \\
\text { LOOK AT OBJECT } \\
------ \\
------\end{array}$ & $\begin{array}{l}\text { GO NEXT TO, GO AWAY FROM } \\
\text { LOOK AT OBJECT } \\
\text { LOOK AWAY } \\
\text { LOOK AT OBSERVER }\end{array}$ \\
\hline $\begin{array}{l}29 \\
30\end{array}$ & $\begin{array}{l}\text { MANIP FOOD CLOTHES } \\
\text { MANIP NONFISH OTHER }\end{array}$ & $\begin{array}{l}------ \\
------\end{array}$ \\
\hline 31 & $\begin{array}{l}\text { HELP WITH FOOD CLOTHES } \\
\text { OFFER HELP }\end{array}$ & $\begin{array}{l}\text { MANIP FOOD CLOTHES } \\
----_{-}\end{array}$ \\
\hline 32 & $\begin{array}{l}\text { LOOK AT OBSERVER } \\
------\end{array}$ & $\begin{array}{l}----- \\
\text { MANIP NONFISH OTHER }\end{array}$ \\
\hline 33 & ----- & MANIP UNINTENDED, VERBAL TO ANIMAL \\
\hline 34 & $\begin{array}{l}\text { SMILE } \\
\text { JOKE }\end{array}$ & $\begin{array}{l}------ \\
------\end{array}$ \\
\hline $\begin{array}{l}35 \\
36\end{array}$ & $\begin{array}{l}------ \\
------\end{array}$ & $\begin{array}{l}\text { REPEAT OTHER VERBAL } \\
\text { JOKE }\end{array}$ \\
\hline 37 & $\begin{array}{l}------ \\
-----\end{array}$ & $\begin{array}{l}\text { SMILE } \\
\text { DESCRIBE BY ANALOGY }\end{array}$ \\
\hline 38 & $\begin{array}{l}\text { COMFORT TOUCH } \\
\text { VERBAL TO OBSERVER }\end{array}$ & $\begin{array}{l}\text { COMFORT TOUCH } \\
------\end{array}$ \\
\hline
\end{tabular}


Table 2. Cluster Analysis (continued) ${ }^{a}$

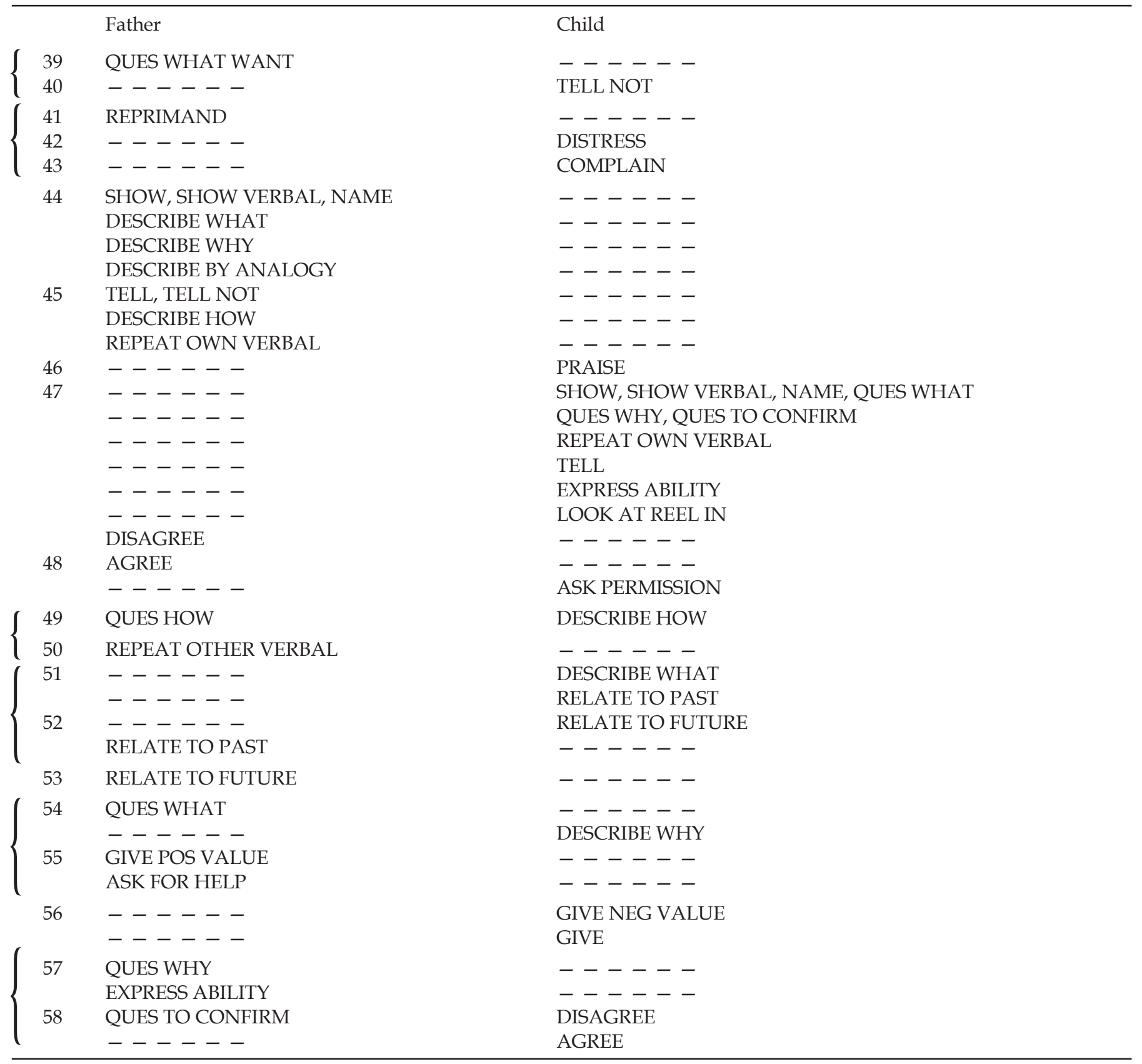

${ }^{a}$ Behaviors that were intercorrelated at $r \geq 0.2$ are listed on the same line. Mean correlations of between 0.1 and 0.2 are shown on adjacent lines and given numerical designations. Mean correlations of between 0.06 and 0.1 are shown by braces in the margin.

often in fathers than in children. Fathers also exhibited a significantly higher frequency of TELL, TELL NOT, GIVE, and TAKE.

Behaviors occurring significantly more frequently in children. Children were more often observed to HOLD
ROD, REEL IN, and TOUCH LINE. Children performed observation, both of persons and of objects, significantly more frequently than their fathers. This was true of all thirteen observation categories. SHOW, SHOW VERBAL, and NAME occurred at a significantly higher frequency in children, though they were 
among the more common behaviors observed in both actors. Several other verbal categories, including QUES WHAT, QUES WHY, ASK FOR HELP, and ASK PERMISSION, were also significantly more frequent in children.

\section{Groupings Within Actor}

Groupings of fishing behaviors. The correlation structure among fishing behaviors was well defined in both actors, with high correlations being exhibited between many of these variables (nearly $10 \%$ of the intercorrelations were $\geq .3$ ). As a result, fishing behaviors were grouped into several homogeneous clusters (father Clusters 1, 2, 8, 9, 12, 14, and 24; child Clusters 1, 4, 6, 8, $9,12,15$, and 23).

In fathers, OR fishing occurred mainly in three large, closely associated clusters (Clusters 16, 17, and 18), in combination with GIVE, TAKE, and MANIP TOGETHER. OR fishing behaviors in children were closely associated among themselves (Clusters 3, 20, 21, and 22).

Groupings of fishing behaviors and verbalizations. Several verbal behaviors were consistently related to observations of fishing. LOOK AT CAST was significantly associated with description (DESCRIBE WHAT, DESCRIBE HOW, and DESCRIBE WHY; $\bar{r}=0.14$ ) and telling (TELL and TELL NOT; $\bar{r}=0.20$ ) in fathers. Similar associations were exhibited for father LOOK AT REEL IN (DESCRIBE WHAT, TELL, and TELL NOT; $\bar{r}=0.15)$. PRAISE in fathers was correlated with five of the six observe person categories $(\bar{r}=0.18)$. In particular, in fathers, PRAISE and LOOK AT CAST were very highly correlated $(r=0.33)$. Father REPRIMAND, in contrast, was poorly related to fishing. In children, PRAISE associated with LOOK AT CAST $(r=0.17)$. Child verbal behaviors were otherwise poorly correlated with observations of fishing, though child QUES HOW was associated with baiting the hook (Clusters 4 and 5).

In fathers, TELL was correlated with six different OR fishing behaviors $(\bar{r}=0.13)$. In children, TELL and TELL NOT exhibited no significant within-actor correlations with fishing or observation and were instead associated mainly with other verbal behaviors (Cluster 47).

The principal nonverbal behavior associated with the show group (SHOW, SHOW VERBAL, NAME) was LOOK AT ANIMAL (fathers $\bar{r}=0.21$; children $\bar{r}$ $=0.17)$, though LOOK AT OBJECT was also correlated with nonverbal SHOW in both actors (fathers $r=0.11$; children $r=0.16$ ). Showing/naming did not associate with fishing behaviors, either within or across actor.

Groupings of verbalizations among themselves. In the correlation analysis, SHOW, SHOW VERBAL, and NAME emerged as a highly intercorrelated cluster, associated within actor less strongly with a number of other verbal behaviors (Clusters 44 and 47). In fathers, descriptions were also highly intercorrelated, occurring, along with TELL and TELL NOT, in the two associated clusters that formed the primary verbal grouping (Clusters 44 and 45). In contrast, descriptions did not form a coherent grouping in children: DESCRIBE HOW and DESCRIBE WHY associated with father questions (Clusters 44 and 45), DESCRIBE WHAT associated with child RELATE TO PAST (Cluster 51), and DESCRIBE BY ANALOGY associated with child SMILE (Cluster 37). As was the case with the show/name cluster, descriptions in both actors were more strongly associated with other verbal behaviors than with any category related to fishing.

Several question categories exhibited a pronounced correlational structure. Child QUES WHAT, QUES WHY, and QUES TO CONFIRM occurred together on the primary verbal cluster (Cluster 47), and QUES HOW and ASK FOR HELP were also strongly associated (Cluster 5). In fathers, on the other hand, questions were distributed singly among five small, unrelated groups (Clusters 49, 54, 55, 57, and 58). PRAISE was also associated with other verbal behaviors: Father PRAISE was correlated with DESCRIBE WHAT, DESCRIBE HOW, QUES HOW, TELL, and QUES TO CONFIRM $(\bar{r}=0.15)$. Father REPRIMAND was associated with QUES HOW, QUES WHY, TELL NOT, RELATE TO PAST, and JOKE $(\bar{r}=0.12)$.

\section{Groupings Across Actor}

Groupings of fishing behaviors. Observations of fishing behavior were distributed in the cluster analysis in close association with their logical fishing counterparts. Observations by children were better correlated with the fathers' fishing on the child's rod than with 
the same actions performed on the fathers' own equipment (Clusters, 1, 12, 15, 16, and 17). The correlations between child observations and father OR fishing were among the highest in the variable set $(r=0.31$ 0.59). Observations by fathers, on the other hand, were best associated with the child's fishing on his own rod (Clusters 1,4, 6, 9, and 15).

The variability in frequency of occurrence across observation behaviors primarily reflected the variation in the frequency of the corresponding fishing behaviors in the dyad partner, rather than a differential tendency to observe particular components of the fishing sequence. The ratio of the frequency of father observation to child fishing, for all fishing behaviors other than UNHOOK FISH, was fairly uniform, averaging about 0.23 ; the ratio of child observation to father fishing (on his own rod and OR combined) was about twice as high, almost 0.50 . The ratio of observation to occurrence in UNHOOK FISH was much higher in both actors: 2.8 for child observation and 1.4 for father.

Some fishing behaviors were closely associated with the corresponding behavior on the dyad partner's rod. For example, TOUCH LINE, and OR TOUCH LINE in the father formed a cluster with TOUCH LINE in the child (Cluster 8). Similar relationships were exhibited in the case of line preparation (Cluster 1), crabbing (Cluster 9), unhooking fish (Cluster 12), and unsnagging the line (Clusters 14 and 15).

Groupings of fishing behaviors with verbalizations. Questions in children commonly occurred in the context of father OR fishing or observation (Clusters 4-5, 18-19). Child QUES HOW was also significantly associated with the father line preparation behaviors in Cluster $1(\bar{r}=0.12)$. ASK FOR HELP in children correlated with father LOOK AT CAST $(r=0.11)$, as well as with the unsnagging behaviors in Cluster $15(\bar{r}=0.15)$. ASK PERMISSION correlated significantly with father OR HOLD ROD $(r=0.13)$ and OR REEL IN $(r=0.13)$. Questions in fathers, in contrast, were poorly related to fishing categories, appearing instead to be most closely associated with child verbalizations.

PRAISE in fathers was associated with child CAST, DESCRIBE HOW, and ASK FOR HELP $(\bar{r}=0.15)$. Child PRAISE associated across actor with father LOOK AT CAST and OR CAST $(\bar{r}=0.11)$.
Groupings of verbalizations among themselves. Questions were often associated across actor with verbal behaviors that could logically be considered as responses. This was particularly true of associations between questions and descriptions [e.g., child QUES WHAT with father NAME $(r=0.25)$ and DESCRIBE WHAT $(r=0.13)$; child QUES HOW with father DESCRIBE HOW $(r=0.12)$; father QUES HOW with child DESCRIBE HOW (Cluster 49); and father QUES WHAT with child DESCRIBE WHY (Cluster 54)]. Other cross-actor associations also appeared meaningful, however. ASK PERMISSION in children was associated with father AGREE, TELL, and TELL NOT $(\bar{r}=0.14)$ : ASK FOR HELP correlated with father PRAISE, QUES WHY, TELL, and QUES TO CONFIRM $(\bar{r}=0.12)$.

Showing/naming by fathers was associated across actor with a considerable variety of child verbalizations (including most of those listed in Cluster 47), while the Show/Name Grouping in children was associated only with father AGREE $(\bar{r}=0.11)$. NAME was, in addition, significantly correlated with itself across actor $(r=0.18)$, as were DESCRIBE WHAT $(r=0.13)$, DESCRIBE HOW $(r=0.11)$, TELL and TELL NOT $(\bar{r}$ $=0.17)$. Child PRAISE correlated across actor with the father TELL Cluster (Cluster 46), while father REPRIMAND associated with child EXPRESS ABILITY and DISTRESS (Cluster 42).

\section{Discussion}

There were a number of identifiable patterns of interaction between fathers and their children that involved the transfer of information in the context of fishing. These patterns, summarized in Table 3, involve close associations among primarily nonverbal behaviors, associations between verbal and nonverbal behaviors, and associations among verbal behaviors that were otherwise poorly related to particular nonverbal events.

The simplest case of primarily nonverbal association involved instances in which a child observed his or her father perform some component of fishing on the father's own equipment, or more commonly, on the child's equipment. This basic pattern was elaborated in those cases in which the father engaged in a fishing action first on his own equipment, and then, 
while the child observed him, performed the same behavior on the child's rod. This was sometimes accompanied by the identical behavior by the child on his own equipment. For example, after touching their own line to check for fish, fathers sometimes leaned over and touched the line on their child's rod, and the child then, too, touched his or her line. Similar associations among fishing categories occurred in the cases of line preparation and unsnagging. These associations of actions probably represent one of the most rudimentary ways in which a father can influence the fishing behavior of his child. By performing an action on the child's rod, the father draws the child's attention to the action, and this may induce the child to repeat the behavior on his own.

Observation is a necessary correlate of both verbal and nonverbal information transfer. It was generally more frequent in children than in their fathers: even when the differential frequency of fishing behaviors was corrected for, children observed their father's fishing at roughly twice the rate that fathers observed children. Beyond this difference, the father's actions on the child's rod appeared to induce greater interest in the child than did the corresponding actions on the father's own rod.

Observation in children probably functions as a means of acquiring information about the correct performance of skilled actions, and the more that these actions are explicitly related to the child himself, apparently, the more interesting they become. Children may simply be most interested in fishing, determin- ing that any actions that occur on their own equipment have a greater probability of leading to the opportunity to fish than would actions on their father's equipment.

Father fishing actions on the child's rod were often accompanied by various verbal behaviors, observations of the child's fishing, and requests by the child for help. For example, a father might observe a failed attempt to cast by the child and then take the child's rod, casting it for him or her. The father then might return the rod to the child, pointing out a particular aspect of the movement or else giving a brief piece of advice on what the child might do next time. In such cases, the father not only provides a demonstration, but also verbally conveys some of his previous experience to the child.

During the portion of the child's fishing cycle that involves reeling in the line and casting or letting out line, fathers commonly produced commands and simple explanations. Such verbalizations also occurred while the father engaged in actions on the child's rod, but in these cases they appear to have been induced by the act of observing the child performing an action. Related associations were observed in the case of PRAISE, which in fathers was the single verbalization most commonly associated with observations of child fishing, particularly casting. Praise by fathers appears to serve the immediate function of confirming to the child that an action was performed correctly. Reprimands occurred more rarely and were unrelated to specific fishing behaviors.

Table 3. The Primary Patterns of Teaching Interactions between Fathers and their Children on Matapeake Pier ${ }^{a}$

\begin{tabular}{|c|c|c|}
\hline Child & Father & Outcome \\
\hline Observe father & $\begin{array}{l}\text { Fish on child's equipment } \\
\text { (fish on own equipment) }\end{array}$ & Child fishes on own equipment \\
\hline $\begin{array}{l}\text { Fish together } \\
\text { (Observe animal) }\end{array}$ & (Observe animal) & Father show/show verbal/name \\
\hline Child verbalize & L & Father show, name \\
\hline Question & $\longrightarrow$ & Father describe \\
\hline
\end{tabular}

${ }^{a}$ Behaviors in parentheses contribute relatively less to the pattern than do the other behaviors. 
The most complex pattern of information transfer observed in this study involved associations of commands and descriptions with simultaneous manipulation of fishing equipment. On such occasions, the father might hold onto his child's rod at the same time as the child, usually putting his arms around the child in order to grasp the rod with both hands. He would then proceed to direct the child's actions very explicitly, giving commands, rules of action and sometimes drawing him physically through the action sequence.

In both fathers and children, behaviors involving showing, description, questioning, and telling were highly intercorrelated, forming several coherent groups and associations. Such associations range in complexity from single directives to action to complex groupings involving both verbal and nonverbal behaviors. One of the most unitary and pervasive of these groupings involved the association of SHOW, SHOW VER$\mathrm{BAL}$, and NAME. This group of behaviors appeared to be unrelated to fishing behaviors, OR fishing, or observation either within or across actor, but they were strongly associated with observations of objects and animals. The show/name group seems to represent a stable behavioral pattern, common to both parents and children, that serves to influence another person's attention to objects in the environment and to convey information about their attributes.

Verbalizations by one actor were also associated with their logical counterparts in the other actor. Fathers showed and named in response to a variety of child verbalizations, while both actors responded to questions with descriptions. Other associations among verbal behaviors were less readily interpreted, however. In some instances a verbalization by one actor appeared to facilitate the same type of verbal behavior in the other. This occurred in the case of NAME, DESCRIBE WHAT, DESCRIBE HOW, TELL, TELL NOT, and QUES TO CONFIRM. These were not instances of echoing another's words, but rather involved the production of a nonidentical behavior in the same category. The father might, for example, name an object, and the child would then name the object in different terms.

Mechanisms of Information Transfer

The behavioral mechanisms of information transfer in the interaction between fathers and their children on
Matapeake Pier display a consistent, readily interpretable structure. The occurrence of such identifiable patterns of association suggests that teaching is not simply a composite of individual responses to particular stimuli. It appears, instead, to possess a coherent organization, which might easily be broadly applicable to other tasks and other human populations.

The patterns evident in teaching were dependent on a number of different variables. One finding is the suggestion that there are fundamental distinctions in the behaviors used in transmission, depending on the nature of the information involved. Mechanisms of teaching and learning may be particular to either skill transfer or the conveyance of object attributes. On the pier, object attributes were communicated by verbal and nonverbal showing and by descriptions. Skill information, on the other hand, was conveyed by doing a task for someone in their presence, by telling, and giving rules of action. These results imply that teaching behaviors may not function as indiscriminate carriers of information (Cloak, 1975), but rather display consistent dependencies on information content.

Another general principle is suggested by the occurrence of three distinguishable patterns in the role differentiation of behaviors. Certain behaviors, for example, showing and naming, were elicited and displayed in a very similar manner in fathers and in children. Role differences in other behaviors, however, were suggestive of ontogenetic changes, both in organization and in function. Some behaviors, such as asking questions or giving descriptions, served the same function in both actors but differed in their frequency of occurrence and in their degree of organization. Other behaviors, such as those involved in giving a demonstration, or giving praise and telling, displayed different functional associations in fathers and children. These contrasting sequences of development, one involving early emergence of functional associations, the other entailing a progressive change in function with age, may reflect a fundamental distinction in the development of complex behavior patterns.

The behaviors involved in the transmission of culture in humans were probably subject to selective pressures that shaped their evolution to their present form. The evolutionary study of these patterns of behavior is problematic, however, since no gradual phylogenetic continuum in these behaviors exists from which to infer their evolutionary development. Instances of cultural transmission in nonhuman animals appear pri- 
marily to involve observational learning, and there are few indications of teaching or even modeling behaviors in nonhuman species (Hinde, 1974; Lancaster, 1975; Bonner, 1980; Mundinger, 1980).

There are, however, two sources of indirect evidence bearing on the evolution of modes of cultural transmission. The first involves comparisons among different human societies to detect common, and therefore presumably primitive, mechanisms of cultural transmission (Blurton Jones and Konner, 1976). Such research in the past has been limited by the absence of data on which to base comparisons. The results of this study provide a baseline source of behavioral data concerning a task that is culturally transmitted in a wide variety of human societies. It is hypothesized that the patterns of transmission behaviors evident in the present study would also be evident in other cultures that engage in fishing, in spite of the differences in actual fishing techniques. Were this to be borne out, systematic comparisons between our findings and similar research on fishing in other cultures could provide insight into the evolution of transmission mechanisms.

The second source of evidence is derived from the analysis of particular behavior patterns. The high degree of organization in the show/name group and the consistency of its occurrence across actor suggest that this pattern of behavior might have served as a phylogenetically primitive form of teaching, which, in combination with other behaviors, could have enabled the evolution of more complex forms. As a related example, Bonner (1980) suggests a progression from observational learning to modeling to modeling with reinforcement. The findings presented in this study are consistent with this progression, but only in the case of the transfer of skill information. The inclination to transmit information about object attributes may represent an evolutionary novelty that enabled the diversification of teaching behaviors in early human societies. It seems likely that a serious search for analogs to showing and modeling in nonhuman animals would help to clarify the nature of the evolutionary change and to cast light on the origins of teaching behavior.

We would like to thank Drs. Kevin Sullivan, John Falk, and John Balling for the use of the facilities of the Smithsonian Institution's Chesapeake Bay Center for Environmental Studies and for their support during this study, and Dr. Peter Stacy for his useful comments on this manuscript. In addition, we would like to extend our gratitude to the fishermen of Maryland and their children for their participation.

\section{References}

Barkow, J. H. Biological evolution of culturally patterned behavior. In The Evolution of Human Social Behavior, J. Lockard (Ed.). New York: Elsevier, 1980, pp. 277-296.

Barnett, S. A. The "instinct to teach." Nature 220: 747-749 (1968).

Bekoff, M. Animal play: Problems and perspectives. In Perspectives in Ethology, 2nd ed. P. P. G. Bateson and P. H. Klopfer (Eds.). New York: Plenum, 1976, pp. 165-188.

Bekoff, M. Socialization in mammals with an emphasis on nonprimates. In Primate Bio-Social Development, S. Chevalier-Skolnikoff and F. E. Poirier (Eds.). New York: Garland Press, 1977, pp. 603-636.

Blurton Jones, N. Characteristics of ethological studies of human behaviour. In Ethological Studies of Child Behaviour, N. Blurton Jones (Ed.). London: Cambridge Univ. Press, 1972, pp. 3-33.

Blurton Jones, N., and Konner, M. J. Kung knowledge of animal behavior. In Kalahari Hunter-Gatherers, R. B. Lee and I. DeVore (Eds.). Cambridge: Harvard Univ. Press., 1976, pp. 325-348.

Bonner, J. T. The Evolution of Culture in Animals. Princeton, NJ: Princeton Univ. Press, 1980.

Cloak, F. T. Is a cultural ethology possible? Human Ecology 3(3): 161-182 (1975).

Davis, J. M. Imitation: A review and critique. In Perspectives in Ethology, 2nd ed. P. P. G. Bateson and P. H. Klopfer (Eds.). New York: Plenum, 1973, pp. 43-72.

Dawkins, R. The Selfish Gene. Oxford: Oxford Univ. Press, 1976a.

Dawkins, R. Hierarchical organization: A candidate principle for ethology. In Growing Points in Ethology, P. P. G. Bateson and R. A. Hinde (Eds.). London: Cambridge Univ. Press, 1976b, pp. 7-54.

DeGhett, V. J. Hierarchical cluster analysis. In Quantitative Ethology, P. W. Colgan (Ed.). New York: Wiley, 1978, pp. 115-144.

Diamond, J. An ethological view of parent-child social interactions and their relationship to exploratory behavior. Unpublished manuscript, 1981.

Dixon, W. J., and Brown, M. B. BMDP Biomedical Computer Programs. Berkeley: Univ. California Press, 1979.

Ewer, R. F. The “instinct to teach.” Nature 222: 698 (1969).

Hays, W. L. Statistics. New York: Holt, Rinehart, and Winston, 1963. 
Hinde, R. A. Biological Basis of Human Social Behavior. New York: McGraw Hill, 1974.

Hull, C. H., and Nie, N. H. SPSS Update. New York: McGraw-Hill, 1979.

Humphrey, N. K. Predispositions to learn. In Constraints on Learning, R. A. Hinde and J. Stevenson-Hinde (Eds.). London: Academic Press, 1973, pp. 301-304.

Itani, J. On the acquisition and propagation of a new food habit in the natural group of the Japanese monkey at Takasaki-Yama. Primates, 1: 84-86 (1958).

Kawai, M. Newly-acquired pre-cultural behavior of the natural troop of Japanese monkeys on Koshima Islet. Primates 6: 1-30 (1965).

Lancaster, J. B. Primate Behavior and the Emergence of Human Culture. New York: Holt, Rinehart and Winston, 1975.

Lorenz, K. Methods of approach to the problems of behavior. In The Harvey Lectures 1958-1959, Series LIV. New York; Academic, 1960.

Lumsden, C. J., and Wilson, E. O. Genes, Mind and Culture, the Coevolutionary Process. Cambridge: Harvard Univ. Press, 1981.

Marler, P., Hamilton, W. J. Mechanisms of Animal Behavior. New York: Wiley, 1966.

McGrew, W. C. Elements of behavior. In An Ethological Study of Children's Behavior. New York: Academic, 1972, pp. 36-112.

Mundinger, P.C. Animal cultures and a general theory of cultural evolution. Ethology and Sociobiology 1: 183-223 (1980).

Norton Griffiths, M. The organization, control and development of parental feeding in the oystercatcher (Haematopus ostralegus). Behaviour 34: 55-114 (1969).

Smith, P. K., Connolly, K. Patterns of play and interaction in pre-school children. In Ethological Studies of Child Behavior, N. Blurton Jones (Ed). London: Cambridge Univ. Press, 1972, pp. 65-95.

Weigel, R. M., and Johnson, R. P. An ethological classification system for verbal behavior. Ethology and Sociobiology 2: 55-66 (1981).

\section{Appendix A}

\section{Nonverbal Categories}

PREPARE LINE: attach hook, line, or sinker onto own rod, tie rope onto own crab trap, cut off lengths of string for a crab line or otherwise set up own rod, crab line, or trap in preparation for fishing or crabbing.
PREPARE BAIT: take bait from container or cut or pull apart bait to use on own rod or trap.

BAIT HOOK: attach bait onto hook or own rod or onto own crab line or trap.

CAST: cast or attempt to cast own rod.

HOLD ROD: hold own rod while the line is extended out into the water.

REEL IN: reel in line on own rod until bait is out of the water or pull up own crab line or trap out of the water.

REEL IN PARTIAL: reel in line on own rod a short distance, not bringing the bait out of the water or pull up own crab line or trap not bringing the bait out of the water.

TOUCH LINE: touch the line on own rod while it is extended out into the water.

LET OUT LINE: let out baited line on own rod into the water or lower down own crab line or trap into the water.

UNSNAG: pull on snagged line on own rod, untangle own line or net, retrieve own dropped rod or reel, or repair own broken rod, line, trap, or net.

UNHOOK FISH: remove or release crab from trap or line or remove fish from hook.

OR PREPARE LINE: perform PREPARE LINE on dyad partner's rod, crab line, or trap.

OR PREPARE BAIT: perform PREPARE BAIT on dyad partner's rod, crab line, or trap.

OR BAIT HOOK: perform BAIT HOOK on dyad partner's rod, crab line, or trap.

OR CAST: perform CAST on dyad partner's rod.

OR HOLD ROD: perform HOLD ROD on dyad partner's rod, crab line, or trap.

OR REEL IN: perform REEL IN on dyad partner's rod, crab line, or trap.

OR REEL IN PARTIAL: perform REEL IN PARTIAL on dyad partner's rod, crab line, or trap.

OR TOUCH LINE: perform TOUCH LINE on dyad partner's rod. 
OR LET OUT LINE: perform LET OUT LINE on dyad partner's rod, crab line, or trap.

OR UNSNAG: perform UNSNAG on dyad partner's rod, crab line, trap, or net.

MANIP FISH OTHER: manipulate basket, tackle box, bucket, knife, or other fishing- or crabbing-related object not included in previous categories.

MANIP TOGETHER: touch rod, line, trap, bait, bucket or other fishing-related object for more than 5 seconds at the same time as another person.

MANIP UNINTENDED: perform action on rod, line, trap, bait, bucket, or other fishing-related object in a manner that is unrelated to the customary function of that object; usually involves repetitive actions.

MANIP FOOD CLOTHES: eat, drink, or hold food or drink; take off or put on clothing or otherwise adjust clothing.

MANIP NONFISH OTHER: manipulate games, toys, food containers, or other objects not related to fishing and not included in the previous categories.

LOOK AT PREPARE LINE: direct gaze for more than 3 seconds toward person who is performing PREPARE LINE or OR PREPARE LINE.

LOOK AT PREPARE BAIT: direct gaze for more than 3 seconds toward person who is performing PREPARE BAIT or OR PREPARE BAIT.

LOOK AT BAIT HOOK: direct gaze for more than 3 seconds toward person who is performing BAIT HOOK or OR BAIT HOOK.

LOOK AT CAST: direct gaze for more than 3 seconds toward person who is performing CAST or OR CAST.

LOOK AT REEL IN: direct gaze for more than 3 seconds toward person who is performing HOLD ROD, REEL IN, REEL IN PARTIAL, LET OUT LINE, OR HOLD ROD, OR REEL IN, OR REEL IN PARTIAL, or OR LET OUT LINE.

LOOK AT UNSNAG: direct gaze for more than 3 seconds toward person who is performing UNSNAG or OR UNSNAG.

LOOK AT UNHOOK FISH: direct gaze for more than 3 seconds toward person who is performing UNHOOK FISH.
LOOK AT OBJECT: direct gaze for more than 3 seconds toward the water, sky, boats, the Bay Bridge, osprey nest or other physical object in the vicinity of the pier.

LOOK AT LINE: direct gaze for more than 3 seconds toward a rod, line, crab line, or crab trap.

LOOK AT BAIT: direct gaze for more than 3 seconds toward a baited hook, crab line, or crab trap.

LOOK AT ANIMAL: direct gaze for more than 3 seconds toward a fish, crab, bird, or other living animal.

LOOK AT OBSERVER: direct gaze for more than 3 seconds toward observer.

LOOK AWAY: turn gaze away from dyad partner while dyad partner is directing verbal or nonverbal behaviors to subject.

SMILE: smile, laugh, or squeal in vicinity of dyad partner.

DISTRESS: frown, whine, cry, or scream in vicinity of dyad partner.

AGGRESS: push, shove, hit, spank, or drop dyad partner.

COMFORT TOUCH: kiss, hug, pat on head or stomach, touch hair of, hold hands with, or carry on piggyback dyad partner.

TAKE: take object from or move object out of reach of dyad partner.

SHOW: point to an object, hold up an object for dyad partner to see or otherwise nonverbally direct dyad partner's attention to an object.

GO NEXT TO: move to a distance of less than 1 meter from dyad partner from a distance of more than 10 meters from dyad partner and do not engage in HOLD ROD or OR HOLD ROD.

GO AWAY FROM: move to a distance more than 10 meters from dyad partner from a distance of less than 1 meter from dyad partner and do not engage in HOLD ROD or OR HOLD ROD.

FISH NEXT TO: move to a distance of less than 1 meter from dyad partner from a distance of more than 10 meters from dyad partner and engage in HOLD ROD or OR HOLD ROD. 
FISH AWAY FROM: move to a distance of more than 10 meters from dyad partner from a distance of less than 1 meter from dyad partner and engage in HOLD ROD or OR HOLD ROD.

HELP FOOD CLOTHES: give food or drink to dyad partner, feed dyad partner, give clothing to, or adjust clothing on dyad partner.

ATTEND TO OTHER: direct gaze for more than 3 seconds or engage in other nonverbal behaviors to nondyad person while he or she is directing verbal or nonverbal behaviors to subject.

OFF OF PIER: move off the pier or down the pier out of the observer's view.

\section{Verbal Categories}

CALL: tell dyad partner to come or call by name.

SHOW VERBAL: verbally direct dyad partner's attention to an object; tell to look.

TELL: tell dyad partner to perform a specific action; command to do.

TELL NOT: tell dyad partner to stop performing some action or to delay the performance of some action; tell to stop, wait, or don't do.

NAME: make verbal comment to dyad partner of five words or less about an object that gives a name to the object or briefly describes observable characteristics of the object.

DESCRIBE WHAT: make verbal comment to dyad partner of greater than five words that gives observable characteristics of the object.

DESCRIBE HOW: give dyad partner verbal directions on how to perform a particular action.

DESCRIBE WHY: give dyad partner a verbal comment that relates to the history, context, or meaning of an object.

DESCRIBE BY ANALOGY: verbally describe to dyad partner the characteristics of an object by relating it to the properties of another object.

DESCRIBE BY EXAMPLE: verbally describe to dyad partner the characteristics of an object by relating it to a person's actions on the same or a similar object.
RELATE TO PAST: verbally comment to dyad partner recalling an event that occurred more than 24 hours in the past.

RELATE TO FUTURE: verbally comment to dyad partner referring to an event that is anticipated to occur more than 24 hours in the future.

QUES WHAT: ask dyad partner a question about the observable characteristics of an object.

QUES HOW: ask dyad partner a question about how to perform a particular action on an object.

QUES WHY: ask dyad partner the reason for a particular attribute or action.

QUES WHAT WANT: ask dyad partner what they want or would like to do.

QUES TO CONFIRM: ask dyad partner how they are, whether they performed an expected action, whether they can perform an intended action or whether they approve of a past action.

AGREE: verbally agree with dyad partner; say yes.

DISAGREE: verbally disagree with dyad partner; say no.

GIVE POS VALUE: verbally comment to dyad partner expressing like, attraction or otherwise favorable impression about an object.

GIVE NEG VALUE: verbally comment to dyad partner expressing dislike, repulsion, or otherwise unfavorable impression about an object.

PRAISE: verbally compliment an action or quality of dyad partner.

REPRIMAND: verbally predict to dyad partner harmful or negative consequences of his action.

COMPLAIN: verbally express sadness, discomfort, disappointment, pain or hunger to dyad partner.

SAY DISLIKE: verbally express anger at dyad partner.

EXPRESS ABILITY: verbally comment to dyad partner expressing ability or intent to perform an action.

OFFER HELP: verbally ask dyad partner if he or she would like assistance in performing some action.

ASK FOR HELP: verbally express to dyad partner inability to perform some action or desire for assistance in performing some action. 
ASK PERMISSION: verbally request permission from dyad partner to perform some action.

JOKE: make a verbal remark to dyad partner for the purpose of eliciting laughter.

REPEAT OWN VERBAL: repeat own verbal comment to dyad partner immediately after it was said.

REPEAT OTHER VERBAL: repeat a verbal comment of dyad partner immediately after it was said.
VERBAL TO OTHER: engage in verbal exchange with a non-dyad person other than observer.

VERBAL TO OBSERVER: engage in verbal ex change with the observer.

VERBAL TO ANIMAL: verbalize to an object or animal or make sounds as if they emanated from an object or animal. 